Voces

\section{De colonos a ciudadanos: el caso} de Isla Mayor

\author{
Assumpta Sabuco Cantó \\ Dpto. de Antropología Social. Universidad de Sevilla
}

En el 2001, Villafranco del Guadalquivir (Sevilla) cambió su denominación por el de Isla Mayor, lo que supuso una reafirmación de su identidad municipal, obtenida en 1994 tras una prolongada lucha por la autonomía y el cambio de colonos a ciudadanos entre sus habitantes. Sus características sociales encerraban un gran interés para analizar las relaciones existentes entre identidades e identificaciones políticas, máxime cuando, desde principios de siglo, fue objeto de polémica por los sucesivos intentos de colonización.

Si el concepto de identidad se ha ido consagrando como una de las temáticas con mayor interés en las ciencias sociales y en la antropología en particular, su uso en las políticas sociales ha ido creciendo. En este sentido, los procesos de colonización permiten analizar cómo se efectúan las distintas políticas de poblamiento, cómo se organizan las movilizaciones locales y de qué forma influyen en estos procesos los sistemas de identidades. Evitar las frecuentes reificaciones por las que la identidad o bien se cosifica o acaba diluida en elecciones individuales, implica atender a la articulación de la etnicidad, las culturas de trabajo y los sistemas de sexo-género como variables estructurales. Las características de la dinámica identitaria, el carácter procesual con el que los colectivos sociales construyen y delimitan las identificaciones locales adquieren un especial significado en el caso de Isla Mayor. Con esta denominación se hace referencia tanto a un espacio "natural" ubicado en las marismas del Guadalquivir, demarcado por los brazos de los ríos, como a un municipio relativamente reciente que fue transformado y colonizado por andaluces y valencianos a partir de dos núcleos principales de poblamiento: El Puntal y Alfonso XIII, tras el fracaso de las compañías que se sucedieron a principios de siglo.

Las características de la estructura local que fue consolidándose desde los años cuarenta y los movimientos segregacionistas que buscaban el reconocimiento administrativo y la autonomía de estos poblados, ligados a la producción arrocera, convertían Isla Mayor del Guadalquivir en un auténtico laboratorio para el estudio de las identidades y de las identificaciones locales (consultar de forma complementaria reseña en p. 126).

En primer lugar, por el carácter activo de la producción social del espacio y de las representaciones territoriales que dan cuenta de las circunstancias históricas y de las relaciones de poder entre los sistemas identitarios a nivel intra y extralocal. La conflictiva lucha por los derechos territoriales de unos grupos frente a otros permitía cuestionar la consideración de las marismas como un espacio "natural" o "salvaje" y analizar los procesos por los que los grupos locales reivindican un espacio vivido como propio así como las apropiaciones que se efectúan desde distintas instituciones y or- ganismos políticos. El carácter multiétnico de estos poblados y su dedicación económica al arroz desde posiciones enfrentadas unos, los valencianos, como colonos y otros, los andaluces, como jornaleros-, evidencia la articulación de la etnicidad, las culturas del trabajo y los procesos de generización de estos hombres y mujeres del Arroz.

En segundo lugar, pese a las directrices que priorizan la concentración administrativa y la integración de diversos núcleos de poblamiento, la proliferación de movimientos locales por la independencia municipal han cuestionado la ordenación territorial de la política estatal y autonómica desde los años ochenta.

El triunfo en la colonización de Rafael Beca así como el intento frustrado de autonomía municipal se apoyó en el contexto político de la Dictadura pero no fue ajeno a la estructura social que se estaba consolidando en la Isla. El protagonismo del primer núcleo de población, Alfonso XIII, durante la Compañía de los ingleses, se vio disminuido con la llegada de "colonos" valencianos y su instalación en El Puntal. La inauguración de ese enclave, como una muestra de la política franquista y el cambio de la denominación tradicional por Villafranco del Guadalquivir, reflejaba una dinámica local que no había sino comenzado. Durante las décadas de los 40 y 50 del pasado siglo XX el inicio de la explotación arrocera y la marcada controversia en torno a estos "orígenes" sólo pueden explicarse atendiendo a los factores estructurales. Para los jornaleros del entorno, las transformaciones económicas se remontaban a principios de siglo, mientras que para Rafael Beca y para los valencianos, el inicio de la verdadera coIonización se sitúa tras la Guerra Civil.

Para los valencianos, que llegaron atraidos por las facilidades para acceder a la tierra que les ofrecía la Compañía, "su" triunfo se apoya en una peculiar forma de cultivar, que garantizaba la transformación de la marisma en un espacio arrocero frente al anterior

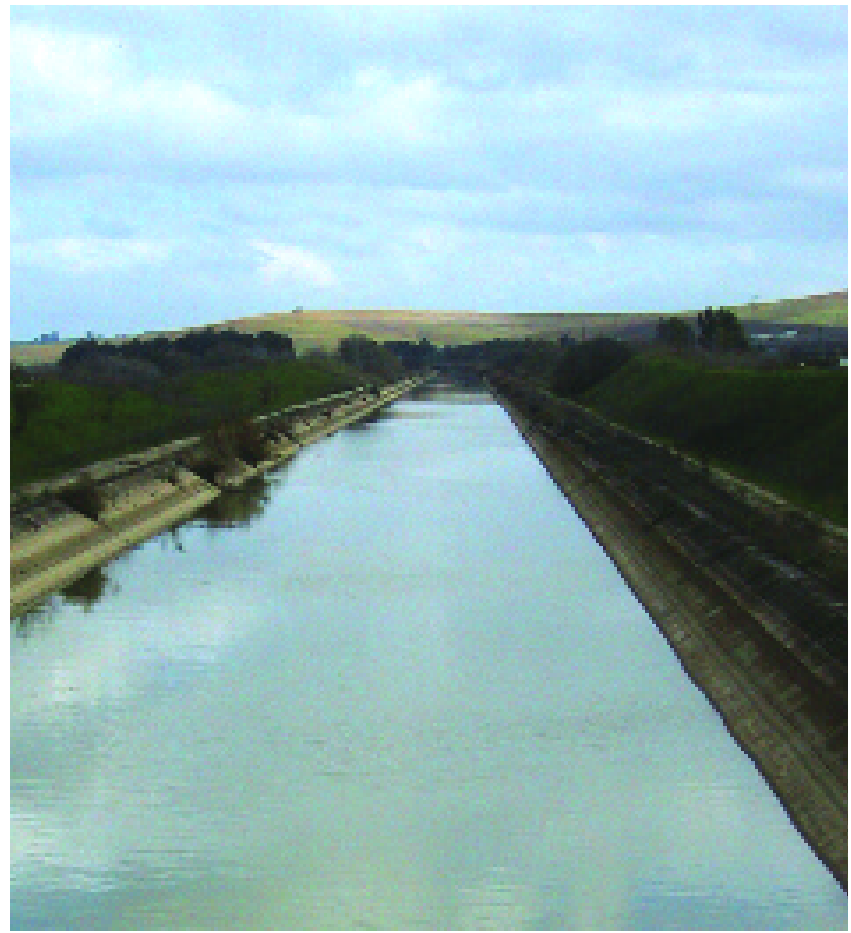

Canal del Bajo Guadalquivir. Foto: Manuel Calzada 
predominio de la ganadería. Para los jornaleros andaluces ya asentados en la capital de la Isla, Alfonso XIII, ese "triunfo" fue el resultado de la injusta política de Rafael Beca, que favoreció a éstos en lugar de a los habitantes del entorno.

En su construcción de la memoria local, los "colonos" valencianos siguen enfatizando un "saber hacer", un modo de vida ligado al cultivo del arroz en el que el esfuerzo, la dedicación y el sacrificio permitieron superar las dificultades. Unas características que aún hoy sirven para legitimar la posición que alcanzaron y que se proyectan no sólo hacia el pasado sino también hacia el futuro agrícola de la Isla, pese a los cambios introducidos en el nivel de la producción y en la organización social del trabajo que ha ido experimentando el cultivo arrocero.

Las divisiones y categorias administrativas que garantizan un determinado funcionamiento en la gestión del espacio ejercen un importante papel en los procesos de identificación, especialmente cuando el territorio se convierte en clave de disputa entre, al menos, dos núcleos poblacionales que aspiran a la propiedad y autogestión de un espacio "común", "nuestro", como en el caso de la Isla enfrentada a su cabecera municipal, La Puebla del Río.

La legislación diferencia, mediante un recurrente argumento basado en la identidad, los derechos municipales y los de otras entidades locales de ámbito territorial inferior. Ser o no municipio supone poseer una identidad local reconocida jurídicamente - y constituir un colectivo legalmente homogéneo- así como disponer de dotación de servicios urbanos y gozar de una mayor autogestión de los recursos propios. Aunque la mayor parte de las delimitaciones socio-políticas se justifiquen por una búsqueda de eficacia y rentabilidad en la organización territorial y por la mayor "cercanía" a los ciudadanos, la misma estructuración de las entidades de población refleja unas políticas de desigualdad que hay que cuestionar. Generalmente, ciertos criterios, como la densidad de población, o la proximidad a los habitantes, se presuponen como condiciones necesarias para ordenar eficazmente el territorio. De manera que, a menor población y mayor distancia entre los núcleos, mayor la dependencia de las grandes entidades urbanas. Al invertir las relaciones entre ordenación del territorio y jerarquización social, la legislación justifica la autonomía de las localidades que ya han sido reconocidas como "pueblo", y silencia las deficiencias que sufren los que aún no lo son al igual que las demandas y reivindicaciones colectivas para serlo.

Según la Ley de Demarcación Municipal de la Junta de Andalucía, ser pueblo se enmarca dentro del marco de política global del Estado, que representa el común denominador normativo (Ley 7/1985, de 2 de abril). Del mismo modo, la Carta Europea de Administración Local de Estrasburgo, de 1985, está consagrada al principio de autonomía local por la que se reconoce: "el derecho y la capacidad efectiva de las Entidades Locales, de ordenar y gestionar una parte importante de los asuntos públicos, en el marco de la Ley, bajo su propia responsabilidad y en beneficio de sus habitantes..."

Pero, pese a la defensa a ultranza de las voluntades de los ciudadanos, de las localidades en las que habitan, el ámbito legislativo ignora las demandas y la especificidad de ciertos colectivos sociales que, muchas veces, son definidos y tienen existencia a través de las reglamentaciones jurídicas.

\section{Información Pues valdrá como ejércitos el miedo}

Entrevista efectuada por Juán F. Ojeda y

Águeda A. Villa

Este endecasílabo de Quevedo -Pues valdrá como ejércitos el miedo- ha sido elegido por Juan Villa como significativo título de su novela, que se encuentra en proceso de publicación y una de cuyas páginas hemos utilizado en nuestro previo artículo sobre los Paisajes coloniales del Bajo Guadalquivir (ver p. 43-51), ya que su referente es El Abalario, espacio arenoso tradicionalmente baldío y convertido en eucaliptal por el Patrimonio Forestal del Estado, tras la Guerra Civil.

Juan Villa es profesor de literatura, ejerce la crítica literaria, colabora asiduamente en la prensa y ha publicado, hasta ahora, algunos relatos cortos, pero por fin -y para regocijo de quienes compartimos con él inquietudes- se ha embarcado en una larga investigación cuyo fruto es la novela que presentamos y a cuyo texto original mecanografiado hemos tenido privilegiado acceso. Son precisamente la propia potencia del texto como nuestra cercanía a Juan y, también, nuestros intentos de recuperar la Geografía como disciplina fronteriza y de sintesis que nos permita acercarnos al paisaje desde una convergencia de miradas y percepciones diversas los factores que nos empujan a proponerle que nos presente él mismo su novela, utilizando la entrevista como soporte textual.

Cien años de soledad, Ágata ojo de gato... ¿Puede enmarcarse tu novela en la línea épica o mítica de un territorio?

Sí y no. Sí, porque mi novela busca la recuperación de un territorio como las que habéis citado y muchas otras. No, porque la clave mítica de García Márquez o Caballero Bonald se pierde aquí o, mejor dicho, se transforma en una visión que podríamos llamar paródica, ya que los hechos que se narran no tienen salvación posible, son una tragicomedia muy de la España de la época, una historia y unos paisajes que carecen de la grandeza que parece pedir una creación épica o mitificadora. Si os parece, voy a utilizar párrafos del texto para ir ilustrando las respuestas desde la propia novela:

.. A lo largo de varios miles de años el poblamiento de la zona ha sido discontinuo, débil y disperso. Fue siempre una suerte de más allá, lo que quedaba después de las columnas de Hércules, el remate cenagoso de lo conocido por donde la Tierra se reblandece igual que un espárrago por su extremo tierno anunciando su consumación: el fin del mundo. Una geografía sin Historia si por Historia entendemos los acontecimientos con referencia escrita. Un espacio por el que pasaron de puntillas las diferentes civilizaciones que lo usaron como lenitivo, respiradero libertino en el que sus elementos más oscuros y audaces pudieran deambular sin trabas ni tapujos: contrabandistas, marengos indolentes, rifeños fugitivos, jabegotes, aventureros y gandulería de toda laya la recorrieron sin dejar huella ni memoria, como la blanca sábana de una cama aparece inmaculada mientras millo- 